\title{
Mapping of quantitative trait loci and confirmation of the FAT1 region on chromosome 4 in an F2 population of pigs
}

\author{
Kleibe de Moraes Silva, Débora Martins Paixão, Priscila Vendramini Silva, Bruna Pena Solero, \\ Mario Sérgio Pereira, Paulo Sávio Lopes and Simone Eliza Facioni Guimarães \\ Departamento de Zootecnia, Universidade Federal de Viçosa, Viçosa, MG, Brazil.
}

\begin{abstract}
The objective was to map QTL on porcine chromosome 4 and to associate them with carcass and internal organ traits in an F2 population. The F1 population was produced by outbreed crossing, using two native Brazilian breed Piau boars and 18 commercial sows. A total of $617 \mathrm{~F} 2$ animals issued from $11 \mathrm{~F} 1$ boars and $54 \mathrm{~F} 1$ sows were typed for a total of five microsatellite markers. The data were analyzed by multiple regressions developed for the analysis of crosses between outbred lines, using the QTL Express software. Significant evidence for QTL was found for pig chromosome 4 regarding carcass and internal organ traits. All QTL were detected in the same region of the chromosome, designated FAT1.
\end{abstract}

Key words: fatness, pig production, divergent crosses, microsatellite markers, QTL mapping.

Received: July 10, 2007; Accepted: December 12, 2007.

\section{Introduction}

Knowledge of the genome and the establishment of genetic maps are fundamental for the isolation and characterization of genes of interest (Rothschild and Plastow, 1999). Genetic markers spread across the animal genome are used for the mapping of regions that influence important traits. An appropriate population design is necessary for this purpose, such as the crossing of two lines that differ in the trait studied. It is assumed that in this type of population alternative alleles are fixed in the two lines. Adequate statistical methods then allow identifying the position and estimating the effect of the quantitative trait loci (QTL) on growth, carcass, meat quality and reproductive traits (Bidanel and Rothschild, 2002).

The Brazilian native pig breed Piau is originated from breeds introduced by Portuguese settlers in the XVI century and has also some influence of Dutch and African pig breeds (Vianna, 1985). The main characteristics of these animals are rusticity, adaptability to poor conditions of management and feeding, and a great resistance to diseases. This pig breed is further characterized by low performance, small litter size, and especially large accumulation of subcutaneous fat (Guimarães and Lopes, 2001).

Pig is one the most extensively studied commercial species. Different QTL have been mapped in several

Send correspondence to Simone Eliza Facioni Guimarães. Departamento de Zootecnia, Universidade Federal de Viçosa, Viçosa, MG, Brazil. E-mail: sfacioni@ufv.br. crosses of various breeds, and it is of fundamental interest to know whether similar effects are present in other crosses and, mainly, in commercial populations (Walling et al., 1998). Once the genes and markers have been validated, these data can be used together with traditional methods in marker-assisted selection, to improve the efficiency of breeding programs. Another possibility with a potential to improve breeding programs is the introgression of genes of interest from different breeds. The objective of the present study was to map QTL associated with carcass, carcass cut and internal organ traits on swine chromosome 4 in an F2 population obtained by crossing divergent lines.

\section{Material and Methods}

Formation of the population and collection of phenotypic data were performed at the Pig Breeding Farm of the Department of Animal Science, Federal University of Viçosa (UFV), Viçosa, MG, Brazil. A full description of the experimental F2 population, phenotype measurements and DNA extraction procedures can be found in Band et al. (2005 a, b), Faria et al. (2006), and Peixoto et al. (2006).

The animals were genotyped using five microsatellite markers (SW489, S0301, S0001, S0217 and SW58) (Table 1). The PCR products were submitted to fragment analysis in an ABI PRISM 310 automatic sequencer (Applied Biosystems), and the amplified fragments were classified using the GENESCAN software (Applied Biosystems). Expected heterozygosity and polymorphic information 
content (PIC) for the population were calculated with the CERVUS v.3.0 software (Kalinowski et al., 2007). The linkage map was constructed using the "build" option of the CRIMAP software (Green et al., 1990).

QTL were mapped in the F2 population with the QTL Express software (Seaton et al., 2002), using the sexaverage map. The statistical model assumed that the QTL is diallelic, with alternative alleles being fixed in each parental breed (Haley et al., 1994). Genotype QQ was defined as the homozygous genotype of the naturalized Brazilian Piau breed, with effect $a$; genotype qq was defined as the homozygous genotype of the commercial breed, with effect $-a$; and Qq was defined as the heterozygous genotype, with effect $d$. The probability of each F2 individual showing each one of the three QTL genotypes was calculated according to the genotypes of the markers at intervals of $1 \mathrm{cM}$ along the chromosome. The additive fraction of F2 phenotypic variance explained by a QTL was computed in each breed, i.e., $h_{Q}^{2}=a^{2} / 2 \sigma_{y}^{2}$, as described by Pérez-Enciso et al., 2000.

The following statistical model was adopted:

$$
Y_{i j k l}=S_{i}+L_{j}+H_{k}+\left(C_{i j k l}-\bar{C}\right) b+c_{a} a+c_{d} d+e_{i j k l}
$$

where $Y_{i j k l}=$ phenotype; $S_{i}=$ fixed effect of sex $i, i=1,2$; $L_{j}=$ fixed effect of batch $j, j=1,2,3,4,5 ; H_{k}=$ fixed effect of the halothane genotype $k, k=1(\mathrm{NN}), 2(\mathrm{Nn})$; $\left(C_{i j k l}-\bar{C}\right) b=$ adjustment for covariables (carcass weight for carcass traits, and cold right side weight for cut traits); $e_{i j k l}=$ residual errors.

The additive $\left(c_{a}\right)$ and dominance $\left(c_{d}\right)$ coefficients for a QTL were calculated from the genotypic probabilities, under the assumption that two breeds were fixed for alternative alleles as follows:

$$
\begin{aligned}
& c_{a}=P(Q Q \mid M i)-P(q q \mid M i) \\
& c_{d}=P(Q q \mid M i)
\end{aligned}
$$

where $P(Q Q \mid M i)=$ conditional probability that the QTL alleles are homozygous and originated from the Brazilian naturalized breed; $P(q q \mid M i)=$ conditional probability that the QTL alleles are homozygous and originated from the commercial breed and $\mathrm{D} P(Q q \mid M i)=$ conditional probability that the QTL alleles are heterozygous.

The previous model was fitted every centiMorgan, regressing the phenotypes onto the coefficients $c_{a}$ and $c_{d}$. At each location an $\mathrm{F}$ ratio was calculated, comparing the model with a QTL to the equivalent model without QTL. Estimates for $a$ and $d$ were calculated at the best estimated position with the highest F-ratio. The chromosome-wide significance levels $(\alpha=0.05$ or 0.01$)$ were determined by a permutation test, using the QTL Express software (Churchill and Doerge, 1994), for a total of 10,000 permutations for each trait. Confidence intervals (CI) for QTL location were obtained as suggested by Pérez-Enciso et al. (2000), using the chi-square drop approximation (equivalent to the
LOD score drop approximation). An $F$-statistic is equal to $\chi_{P}^{2} / \mathrm{p}$, approximately, where $\mathrm{p}$ is the number of parameters estimated, in this case, two: the additive and the dominance effects. The $95 \%$ threshold is $\chi_{2,95}^{2}=3.85$. Thus, the $95 \%$ confidence interval limits were obtained at the chromosome locations where the $F$-statistics decreased $3.85 / 2=$ 1.92 units, starting in both directions from the position corresponding to the maximum $F$.

Genome-wide thresholds were obtained applying the Bonferroni correction, as described in Knott et al. (1998) and used by Pérez-Enciso et al. (2000). Supposing that a given value $\mathrm{F}$ corresponds to a chromosome significance level $\mathrm{Pc}$, the genome significance level associated is given by $P G=1-(1-P c)^{19}$, where 19 is the haploid number of pig chromosomes. This formula assumes that lengths and marker spacing in all chromosomes are identical, so that results are to be taken only as approximate.

\section{Results}

The distance comprised by the five microsatellite markers on swine chromosome 4 was $152 \mathrm{cM}$, corresponding to a mean mapping interval of $38 \mathrm{cM}$. The size of the map agrees with those reported in the literature, ranging from $130.1 \mathrm{cM}$ (USDA-MARC.2; Rohrer et al., 1996) to $165.0 \mathrm{cM}$ (PiGMaP.1; Archibald et al., 1995). No change in the order of the markers was observed, in agreement with other studies (Walling et al., 1998; Gerbens et al., 2000). Table 1 summarizes the characteristics of the microsatellite markers used for the mapping of swine chromosome 4 . The PIC values calculated for the parental and F1 generations were low, a finding that might be due to the small number of alleles segregating in this population. However, Botstein et al. (1980) classified markers with a PIC of 0.25 to 0.5 as moderately polymorphic (SW489, S0217 and SW58) and markers with a PIC higher than 0.5 as highly polymorphic (S0301 and S001) and, therefore, both classes are suitable for mapping.

Table 1 - Microsatellite markers used for the mapping of pig chromosome 4.

\begin{tabular}{lrrrrc}
\hline Marker $^{1}$ & Position $^{2}$ & PIC $^{3}$ & HExp. $^{4}$ & HObs. $^{5}$ & $\begin{array}{c}\text { N. of } \\
\text { alleles }\end{array}$ \\
\hline SW489 & 0.0 & 0.32 & 0.58 & 0.68 & 3 \\
S0301 & 33.0 & 0.50 & 0.52 & 0.56 & 3 \\
S0001 & 59.2 & 0.50 & 0.60 & 0.60 & 3 \\
S0217 & 112.0 & 0.41 & 0.57 & 0.73 & 3 \\
SW58 & 152.3 & 0.42 & 0.56 & 0.69 & 4 \\
\hline
\end{tabular}

${ }^{1}$ Reaction conditions: $1 \mathrm{U}$ Taq polymerase, $0.2 \mathrm{mM}$ dNTPs, $0.2 \mu \mathrm{M}$ each forward and reverse primers, $20 \mathrm{mM}$ Tris- $\mathrm{HCl} \mathrm{pH} \mathrm{8.3,50} \mathrm{mM} \mathrm{KCl,}(2$ to $4 \mathrm{mM}) \mathrm{MgCl}_{2}, 25 \mathrm{ng} / \mu \mathrm{L}$ genomic DNA. The final volume was $20 \mu \mathrm{L}$. The PCR fragments were electrophoresed on $8 \%$ polyacrylamide gels. ${ }^{2}$ Position in $\mathrm{cM} ;{ }^{3}$ Polymorphic Information Content (PIC) for the population calculated with the CERVUS v.3.0 software; ${ }^{4}$ expected (HExp) and ${ }^{5}$ observed (HObs) heterozygosities were obtained with the CERVUS v. 3.0 software. 
Most of the QTL affecting carcass and internal organ traits were identified within an interval of approximately 90 to $135 \mathrm{cM}$ on the chromosome. In this region, other authors have identified QTL for performance traits (De Koning et al., 1999; Rattink et al., 2000; Berg et al., 2006) and meat quality traits (Pérez-Enciso et al., 2000). Table 2 shows the maximum likelihood ratios (Fmax) and positions (cM) of the QTL found in the present study and the respective estimates of additive and dominance effects. The chromosome-wide $5 \%$ and $1 \%$ significance thresholds were 4.86 and 6.60 , respectively. The $5 \%$ and $1 \%$ genome-wide statistics were $\mathrm{F}=8.06$ and 9.76 , respectively.

Five significant QTL were identified for carcass traits (Table 2 and Figure 1a), with $\mathrm{p}<0.05$ chromosome-wide for midline backfat thickness after last rib (LR), $\mathrm{p}<0.01$ chromosome-wide for backfat thickness between last 1st2nd lumbar vertebrae (LL) and lower backfat thickness after last lumbar vertebrae (L), $\mathrm{p}<0.05$ genome-wide for backfat thickness at $6.5 \mathrm{~cm}$ from the midline (P2), and $\mathrm{p}<0.01$ genome-wide for bacon depth (BCD). Five QTL were detected for carcass cut traits, with $\mathrm{p}<0.05$ chromosome-wide for loin depth (LD), loin eye area (LEA) and skinless and fatless boston shoulder weight (BSW) (Table 2 and Figure 1b), and $p<0.01$ genome-wide for skinless and fatless ham weight (HW) and skinless and fatless picnic shoulder weight (PSW) (Table 2 and Figure 1c). With respect to internal organ traits, a QTL was observed for heart weight (HEART) $(\mathrm{p}<0.05$ chromosome-wide) (Table 2 and Figure 1c). A more detailed description of all these QTL is provided in Table 2.

\section{Discussion}

For traits related to fat deposition (backfat thickness), QTL were detected in the region between markers S0001 and SW58 (Figure 1a). Although the backfat measures were obtained in different regions, they may represent a single trait, since in this population the phenotypic correlation between these measures ranges from 0.72 to 0.89 (data not shown), thus indicating the presence of one or more genes in this region that act on subcutaneous fat deposition. Possibly, alleles inherited from the naturalized Brazilian Piau breed were responsible for the increased backfat thickness observed in the different regions evaluated, because all $a$ values were positive (Table 2), demonstrating the contribution of Piau alleles to the development of these traits. These results were expected, since this breed is characterized by low performance, small litter size, and especially large accumulation of subcutaneous fat (Guimarães and Lopes, 2001).

The results obtained in the present study are in accordance with other findings reported in the literature. The QTL region for backfat thickness on SSC4 was first identified by Anderson et al. (1994), who mapped QTL influencing performance and fat deposition in animals derived from a cross between wild boars and commercial pigs (Large White). The same region was also detected by Marklund et al. (1999), who used F2 animals of the above mentioned cross and backcrossed them with Large White animals, confirming the presence of the QTL for fat deposition. This region was designed FAT1 (Marklund et al., 1999). In the same region, Malek et al. (2001) also found significant

Table 2 - Summary of the QTL positions $(\mathrm{cM})$, maximum likelihood ratios $\left(\mathrm{F}_{\max }\right)$, phenotypic variance in F2 explained by the QTL $\left(\mathrm{h}^{2}{ }_{\mathrm{Q}}\right)$ in percentage and the respective estimates of additive and dominance effects.

\begin{tabular}{lccrcc}
\hline Trait & Position $^{1}$ & $\mathrm{~F}_{\max }(\mathrm{CI})^{2}$ & $\mathrm{~h}_{\mathrm{Q}}$ & $\mathrm{a}( \pm \mathrm{SE})^{3}$ & $\mathrm{~d}( \pm \mathrm{SE})^{3}$ \\
\hline LR $(\mathrm{mm})$ & 100 & $5.90(69-133)^{*}$ & 8.9 & $1.804 \pm 0.557$ & $1.809 \pm 1.518$ \\
LL $(\mathrm{mm})$ & 105 & $7.83(80-122)^{* *}$ & 11.0 & $2.573 \pm 0.676$ & $2.261 \pm 1.797$ \\
L $(\mathrm{mm})$ & 95 & $6.85(76-126)^{* *}$ & 7.5 & $2.470 \pm 0.854$ & $5.275 \pm 2.344$ \\
P2 $(\mathrm{mm})$ & 112 & $8.99(87-132)^{* * *}$ & 10.3 & $1.555 \pm 0.367$ & $0.309 \pm 0.917$ \\
BCD $(\mathrm{mm})$ & 112 & $10.58(96-126)^{* * * *}$ & 10.9 & $2.966 \pm 0.651$ & $1.687 \pm 1.629$ \\
LD $(\mathrm{mm})$ & 133 & $5.79(111-152)^{*}$ & 8.7 & $-5.387 \pm 1.583$ & $-2.073 \pm 3.277$ \\
LEA $\left.(\mathrm{cm})^{2}\right)$ & 133 & $6.49(114-152)^{*}$ & 9.7 & $-3.597 \pm 0.998$ & $-1.399 \pm 2.068$ \\
HEART $(\mathrm{kg})$ & 90 & $5.77(61-129)^{*}$ & 8.0 & $-0.012 \pm 0.004$ & $-0.013 \pm 0.011$ \\
HW $(\mathrm{kg})$ & 96 & $10.57(81-126)^{* * * *}$ & 11.9 & $-0.195 \pm 0.053$ & $-0.394 \pm 0.146$ \\
BSW $(\mathrm{kg})$ & 117 & $5.56(92-144)^{*}$ & 7.6 & $-0.077 \pm 0.024$ & $0.019 \pm 0.058$ \\
PSW $(\mathrm{kg})$ & 118 & $10.32(98-132)^{* * * *}$ & 12.6 & $-0.180 \pm 0.040$ & $-0.136 \pm 0.098$ \\
\hline
\end{tabular}

${ }^{*} \mathrm{p}<0.05$ chromosome-wide significance; ${ }^{* *} \mathrm{p}<0.01$ chromosome-wide significance; ${ }^{* * *} \mathrm{p}<0.05$ genome-wide significance; $* * * \mathrm{p}<0.01$ genome-wide significance; ${ }^{1} \mathrm{QTL}$ average position in $\mathrm{cM} ;{ }^{2}$ Confidence interval; ${ }^{3}$ Standard error; LR - backfat thickness after last rib; LL - backfat thickness between last 1st-2nd lumbar vertebrae; L - lower backfat thickness after last lumbar vertebrae; P2 - backfat thickness at $6.5 \mathrm{~cm}$ from the midline; BCD bacon depth; LD - loin depth; LEA - loin eye area; HEART - heart weight; HW - skinless and fatless ham weight; BSW - skinless and fatless boston shoulder weight; PSW - skinless and fatless picnic shoulder weight. 

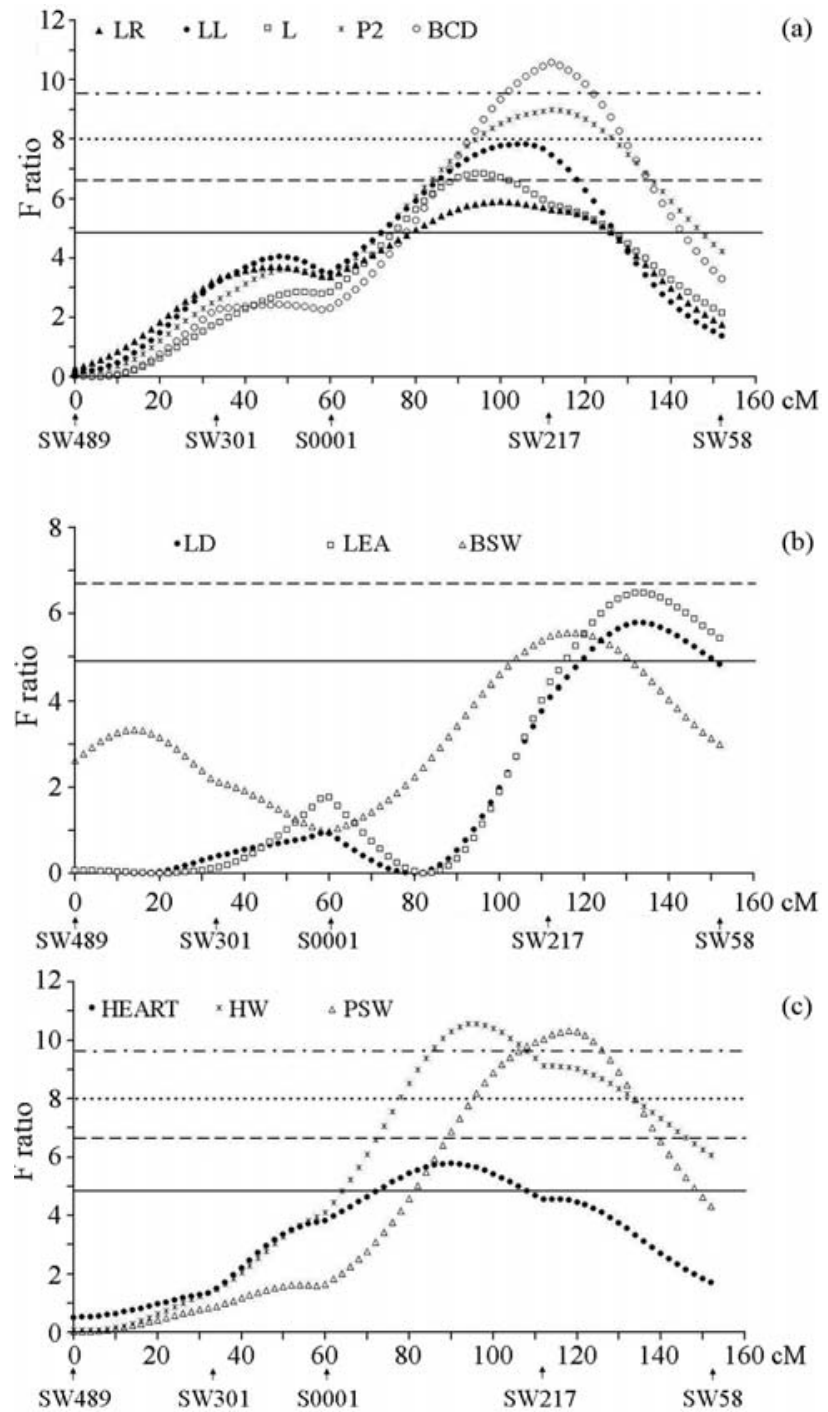

Figure 1 - (a) F ratio estimates for fat thickness: bacon depth (BCD), backfat thickness at $6.5 \mathrm{~cm}$ from the midline (P2), lower backfat thickness after last lumbar vertebrae (L), midline backfat thickness after last rib (LR), backfat thickness between last 1st-2nd lumbar vertebrae (LL). The horizontal lines indicate the levels of significance: chromosome-wide $(5 \%$ $=$ continuous line, $1 \%=$ dashed line $)$ and genome-wide $(5 \%=$ dotted line, $1 \%=$ dot-dashed line). (b) F ratio estimates for loin depth (LD), loin eye area (LEA), and skinless and fatless boston shoulder weight (BSW). The horizontal lines indicate the chromosome-wide $(5 \%=$ continuous line, $1 \%$ $=$ dashed line) levels of significance. (c) F ratio estimates for skinless and fatless ham weight (HW), skinless and fatless picnic shoulder weight (PSW), and heart weight (HEART). The horizontal lines indicate the levels of significance: chromosome-wide $(5 \%=$ continuous line, $1 \%=$ dashed line $)$ and genome-wide $(5 \%=$ dotted line, $1 \%=$ dot-dashed line).

QTL for backfat thickness measured in the lumbar region and at the last rib in F2 animals originated from a cross between Berkshire and Yorkshire pigs. Although we used different breeds from those reported in these studies (Anderson et al., 1994; Marklund et al., 1999; Malek et al., 2001), the same region is likely to be confirmed.

Among the QTL described here, the QTL for bacon depth (BCD) presented the highest $F$ value (10.58) and was detected at position $112 \mathrm{cM}$, within the same interval as the QTL for the other backfat thickness traits (Figure 1a). The estimate of the additive effect for the BCD trait was $2.96 \pm 0.65$ and the QTL found was responsible for $10.9 \%$ of the phenotypic variation, demonstrating the contribution of Piau alleles to the phenotypic expression of this trait, as observed for the other subcutaneous fat measures (Table 2). Similar findings were reported by Peréz-Enciso et al. (2000), who found that the identified QTL were in the expected direction, with Iberian alleles increasing fat deposition and reducing the growth rate and muscle area.

A more detailed study of the FAT1 region was conducted by Berg et al. (2006) to confirm the presence of genes influencing fat deposition on SSC4. The authors used F2 animals originating from a cross between wild boar and Large White pigs (Andersson et al., 1994) and backcrossed them with Large White animals until the sixth generation, in order to reduce the interval of the FAT1 region to less than $20 \mathrm{cM}$. After comparative mapping with the human genome, these authors observed homology between the HSA1q23.3 chromosome region and the FAT1 region. In humans, this region contains approximately 20 genes and, according to these authors, the $L M X 1 A$ and $P B X 1$ genes are the ones most likely to influence fat deposition traits.

QTL for LEA and LD were identified between markers S0217 and SW58, at position $133 \mathrm{cM}$ (Figure 1b). In this population, these two traits show a phenotypic correlation of 0.70 (data not shown), so the QTL were expected to be detected in the same region. The additive effects of LEA and LD were estimated to be $-3.60 \pm 0.99$ and $-5.39 \pm 1.58$, respectively, demonstrating that alleles inherited from the Brazilian naturalized Piau breed were responsible for the reduction in values obtained for the two traits. Pérez-Enciso et al. (2000) observed the presence of a QTL affecting loin eye area at position $83 \mathrm{cM}$ on SSC4. The QTL identified by these authors is close to marker S0214, which is closely related to marker S0217, screened in the present study. LEA is a trait that has been indirectly selected based on backfat thickness, since a reduction in the latter increases the former. The correlation $(-0.25)$ between these two traits observed in this population confirms this finding (data not shown).

The QTL for loin eye area and loin depth were found to be located in a distal region when compared to the QTL for the different subcutaneous fat thickness measures; however, they have overlapping CI's (CI around 69 to 133 for fatness, and between 111 and 152 for muscling). Our finding agrees with the results reported by Andersson et al. (1994), who described non-coincident QTL for growth and fatness, the growth QTL being telomeric with regard to the fatness QTL. A somewhat similar finding was also described by Perez-Enciso et al., (2000), who reported that the QTL locations corresponding to maximum $\mathrm{F}$ for fatness and growth were separated by $8 \mathrm{cM}$ or less, with overlapping CI's. Pointing in a different direction are the findings 
of De Koning et al. (2001), who worked with an experimental cross between Meishan and Dutch Large White and Landrace lines and could not find any QTL for backfat thickness on SSC4, although a suggestive QTL for intramuscular fat was detected on this chromosome when the line-cross approach was used. Unfortunately, we do not yet have data about the fatty acid profile of our $\mathrm{F} 2$ population, so this comparison cannot be made at this point.

QTL for BSW (Figure 1b), HW and PSW (Figure 1c) were identified within an interval of approximately 90 to $120 \mathrm{cM}$, in a region overlapping with the fat deposition QTL. Alleles inherited from the naturalized Brazilian Piau breed were responsible for the decreased muscling traits. Geldermann et al. (2003) observed the presence of QTL for HW and $\mathrm{BSW}$ at position $115 \mathrm{cM}$ on SSC4 in a cross between wild boar and Pietrain pigs; the QTL for HW and BSW were responsible for $5.2 \%$ and $8.3 \%$ of the phenotypic variation, respectively. Possibly, these QTL are the same.

With respect to internal organ traits, a QTL for HEART $(\mathrm{p}<0.05)$ was identified at $90 \mathrm{cM}$ (Figure 1c). Cepica et al. (2003), studying various crosses, found a significant QTL for heart weight on chromosome 4 at position $66 \mathrm{cM}$ in animals originating from a cross between wild European and Chinese Meishan pigs. It is hard to tell if these QTL are the same, since the two studies used different markers, and even the average map may show some differences.

The findings described in the present paper about a similar QTL profile of our crossed Piau pigs and those described for the Iberian (Perez-Enciso et al., 2000) and wild boar crosses (Andersson et al., 1994) support the evidence that our naturalized breeds are derived from European ancestors. Furthermore, the results of the present study show that most significant QTL are located in common regions on porcine chromosome 4 , indicating that the same gene (or genes) is (or are) controlling traits related to subcutaneous fat deposition. Our research team will keep working on SSC4 and on the other pig chromosomes to find more informative markers, related not only to production traits, but also to establish a better evolutionary relationship between the naturalized Piau breed and European animals which might be their ancestors.

\section{Acknowledgments}

This study was supported by FAPEMIG, CNPq, CAPES and FINEP. The collaboration of Marcos Vinícius G.B. Silva from EMBRAPA-CNPGL is acknowledged. We thank Dr. Max Rothschild, coordinator of the US Pig Genome Project, for the donation of the primers for the microsatellite markers.

\section{References}

Andersson L, Haley CS, Ellegren H, Knott SA, Johansson MK, Andersson K, Andersson-Eklund L, Edfors-Lilja I,
Fredholm M, Hansson I et al. (1994) Genetic mapping of quantitative trait loci for growth and fatness in pigs. Science 263:1771-1774.

Archibald AL, Haley CS, Brown JF, Couperwhite S and Mcqueen HA (1995) The PiGMaP consortium linkage map of the pig (Sus scrofa). Mamm Genome 6:157-175.

Band GO, Guimarães SEF, Lopes PS, Schierholt AS, Silva KM, Pires AV, Benevenuto Júnior AA and Gomide LAM (2005a) Relationship between the Porcine Stress Syndrome gene and pork quality trait in F2 pigs resulting from divergent crosses. Genet Mol Biol 28:88-91.

Band GO, Guimarães SEF, Lopes PS, Peixoto JO, Faria AF, Pires AV, Figueiredo FC, Nascimento CS and Gomide LAM (2005b) Relationship between the Porcine Stress Syndrome gene and carcass and performance trait in F2 pigs resulting from divergent crosses. Genet Mol Biol 28:92-96.

Berg F, Stern S, Andersson K, Andersson L and Moller, M (2006) Refined localization of the FAT1 quantitative trait locus on pig chromosome 4 by marker-assisted backcrossing. BMC Genetics 7:17.

Bidanel JP and Rothschild M (2002) Current status of quantitative trait locus mapping in pigs. Pig News Info 23:39-54.

Botstein D, White RL, Skolnick M and Davis RW (1980) Construction of genetic linkage map in man using restriction fragment length polymorphisms. Am J Hum Genet 32:314331.

Cepica S, Stratil A, Kopecny M, Blaskova P, Schroffel J, Davoli R, Fontanesi L, Reiner G, Bartenschlager H, Moser G et al. (2003) Linkage and QTL mapping for Sus scrofa chromosome 4. J Anim Breed Genet 120:28-37.

Churchill GA and Doerge RW (1994) Empirical threshold values for quantitative trait mapping. Genetics 138:963-971.

De Koning DJ, Janss LL, Rattink AP, Oers PA, De Vries BJ, Groenen MAM, Der Poel JJ, De Groot PN, Brascamp EW and Van Arendonk JAM (1999) Detection of quantitative trait loci for back fat thickness and intramuscular fat content in pigs (Sus scrofa). Genetics 152:1679-1690.

De Koning DJ, Rattink AP, Harlizius B, Van Arendonk JAM, Brascamp EW and Groenen MAM (2001) Detection and characterization of quantitative trait loci for meat quality traits in pigs. J Anim Sci 79:2812-2819.

Faria DA, Guimarães SEF, Lopes PS, Pires AV, Paiva SR, Sollero BP and Wenceslau AA (2006) Association between G316A growth hormone polymorphism and economic traits in pigs. Genet Mol Biol 29:634-640.

Geldermann H, Müller E, Moser G, Reiner G, Bartenschlager H, Cepica S, Stratil A, Kuryl J, Moran C, Davoli R et al.(2003) Genome-wide linkage and QTL mapping in porcine F2 families generated from Piétrain, Meishan and Wild Boar crosses. J Anim Breed Genet 120:363-393.

Gerbens F, De Koning DJ, Harders FL, Meuwissen TH, Janss LL, Groenen MAM, Veerkamp JH, Van Arendonk JAM and Te Pas MF (2000) The effect of adipocyte and heart fatty acid-binding protein genes on intramuscular fat and backfat content in Meishan crossbred pigs. J Anim Sci 78:552-559.

Green P, Falls K and Crooks S (1990) Documentation for CRIMAP, v. 2.4. Washington Univ. School of Medicine, St. Louis.

Guimarães SEF and Lopes PS (2001) Uso de recursos genéticos nativos no mapeamento genético de suínos. Ação Ambiental 15(3):27-28. 
Haley CS, Knott SA and Elsen JM (1994) Mapping quantitative trait loci in crosses between outbred lines using least squares. Genetics 36:1195-1207.

Kalinowski ST, Taper ML and Marshall TC (2007) Revising how the computer program CERVUS accommodates genotyping error increases success in paternity assignment. Mol Ecol 16:1099-1106.

Knott SA, Marklund L, Haley CS, Andersson K, Davies W, Ellegren H, Fredholm M, Hansson I, Hoyheim B, Lundstrom K et al. (1998) Multiple marker mapping of quantitative trait loci in a cross between outbred wild boar and Large White pigs. Genetics 148:1069-1080

Malek M, Dekkers JCM, Lee HK, Bass TJ and Rotschild MF (2001) A molecular genome scan analysis to identify chromosomal regions influencing economic traits in the pig. I. Growth and body composition. Mamm Genome 12:630636.

Marklund L, Nystrom PE, Stren S and Andersson L (1999) Confirmed quantitative trait loci for fatness and growth on pig chromosome 4. Heredity 82:134-141.

Peixoto JO, Guimarães SEF, Lopes PS, Soares MAM, Pires AV, Barbosa MVG, Torres RA and Silva MA (2006) Associations of leptin gene polymorphisms with production traits in pigs. J Anim Breed Genet 123:378-383.

Pérez-Enciso M, Clop A, Noguera JL, Óvilo C, Coll A, Folch JM, Babot D, Estany J, Oliver MA, Díaz I et al. (2000) A QTL on pig chromosome 4 affects fatty acid metabolism: Evidence from an Iberian by Landrace intercross. J Anim Sci 78:2525-2531.

Rattink AP, De Koning DJ, Faivre M, Harlizius B, Van Arendonk JAM and Groenen MAM (2000) Fine mapping and imprinting analysis for fatness trait QTLs in pigs. Mamm Genome 11:656-661.

Rohrer GA, Alexander LJ, Hu Z, Smith TPL, Keele JW and Beattie CW (1996) A comprehensive map of the porcine genome. Genome Res 6:371-391.

Rothschild MF and Plastow GS (1999) Advances in pig genomics and industry applications. AgBiotechNet 1:1-7.

Seaton G, Haley CS, Knott SA, Kearsey M and Visscher PM (2002) QTL express: Mapping quantitative trait loci in simple and complex pedigrees. Bioinformatics 18:339-340.

Vianna AT (1985) Os Suínos. 14ª ed. Editora Nobel, São Paulo, $384 \mathrm{pp}$.

Walling GA, Archibald AL, Cattermole JA, Downing AC, Finlayson HA, Nicholson D, Visscher PM, Walker CA and Haley CS (1998) Mapping of quantitative trait loci on porcine chromosome 4. Anim Genet 29:415-424.

\section{Internet Resources}

QTL Express software for the analysis of quantitative trait data, http://www.qtl.cap.ed.ac.uk (January 3, 2007).

Associate Editor: Pedro Franklin Barbosa

License information: This is an open-access article distributed under the terms of the Creative Commons Attribution License, which permits unrestricted use, distribution, and reproduction in any medium, provided the original work is properly cited. 